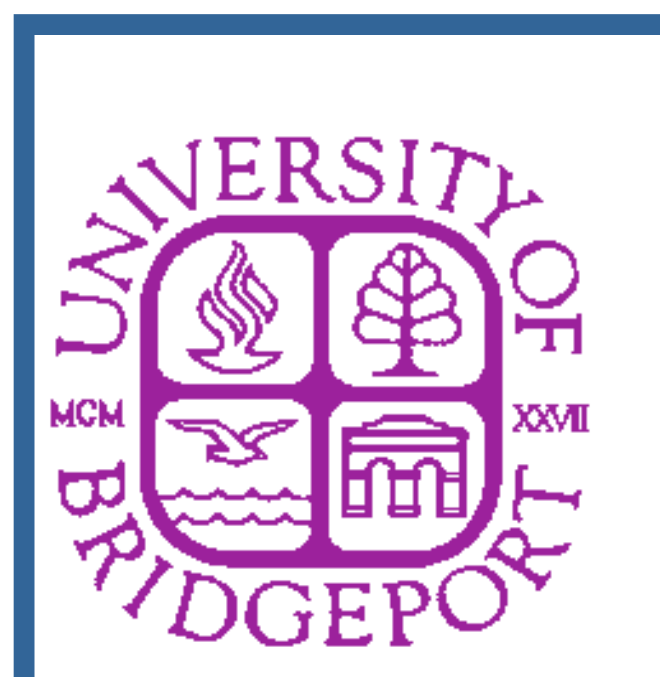

\title{
Computer Aided Design and Development Of a New Solar Panel Tracking System
}

\section{Jeremy (Zheng) Li \\ Department of Mechanical Engineering University of Bridgeport, Bridgeport, CT}

\section{ABSTRACT}

Solar power is an alternative energy resource which will potentially reduce the dependence on environmental energy resources such as coal and petroleum. However, the solar power absorption efficiency in current solar energy panel systems is normally lower that limits the solar system applications. The solar power system needs to be improved including solar panel tracking mechanism to increase the system energy efficiency. To receive the maximum solar energy from sunlight, the tracking mechanism is required in order for solar power system to follow sun's daily and yearly movement. The solar panel system should have the capability to store solar energy while work in rainy, windy, and snowy conditions. Also, the solar power system should be able to withstand the external loads, such as strong wind and heavy snow, to function properly even in severe weather and harsh environment. This paper presents a new type of dual-axial solar tracking mechanism to maximize the solar power absorption. The computer aided 3-D modeling, numerical analysis, and prototype experiments have been performed to design and develop this new solar tracking system.

Keywords: Solar power, green energy, dual-axis, tracking mechanism, wind load, snow load, and system efficiency

\section{INTRODUCTION}

Solar panel system can collect sunlight and convert it to other useful energies. The solar collection efficiency changes with different orientation angles. The optimal solar collection can be achieved when the sunlight is perpendicular to the solar panel. Solar pane tracking mechanism is necessary to orientate the solar system. Using solar power tracking mechanism can orientate solar panel towards to the sun. The sun rises up in the east and sunset in the west each day with its gradual orientation change between the south and north through a full year which causes an incidental angle between solar panel and incoming sunlight. Solar tracking mechanism as a very critical part of the solar power system is aiming at decreasing the incidental angle by orientating the solar pane following sun's movement. There are single-axial and dual-axial tracking mechanisms in current solar powe panel systems. The solar panel system can only orientate along one axis with single axial tracking mechanism to follow the solar azimuth. This singleaxial track mechanism is simple and easy to be controlled. It can be normally applied in the areas with sufficient and stable sunlight intensity. The drawback of single-axial tracking mechanism is that the solar panel in solar power system cannot be always kep perpendicular to the sunlight which causes the efficiency reduction in photoelectric conversion. The dual-axial tracking mechanism consists of dual-axial orientation device which can conduct more complex 3 $\mathrm{D}$ rotation following sun's movement to absorb more solar energy and gain higher system efficiency.

\section{COMPUTER AIDED MODELING}

\section{AND SIMULATION}

This new solar tracking mechanism is shown in Fig. 1.

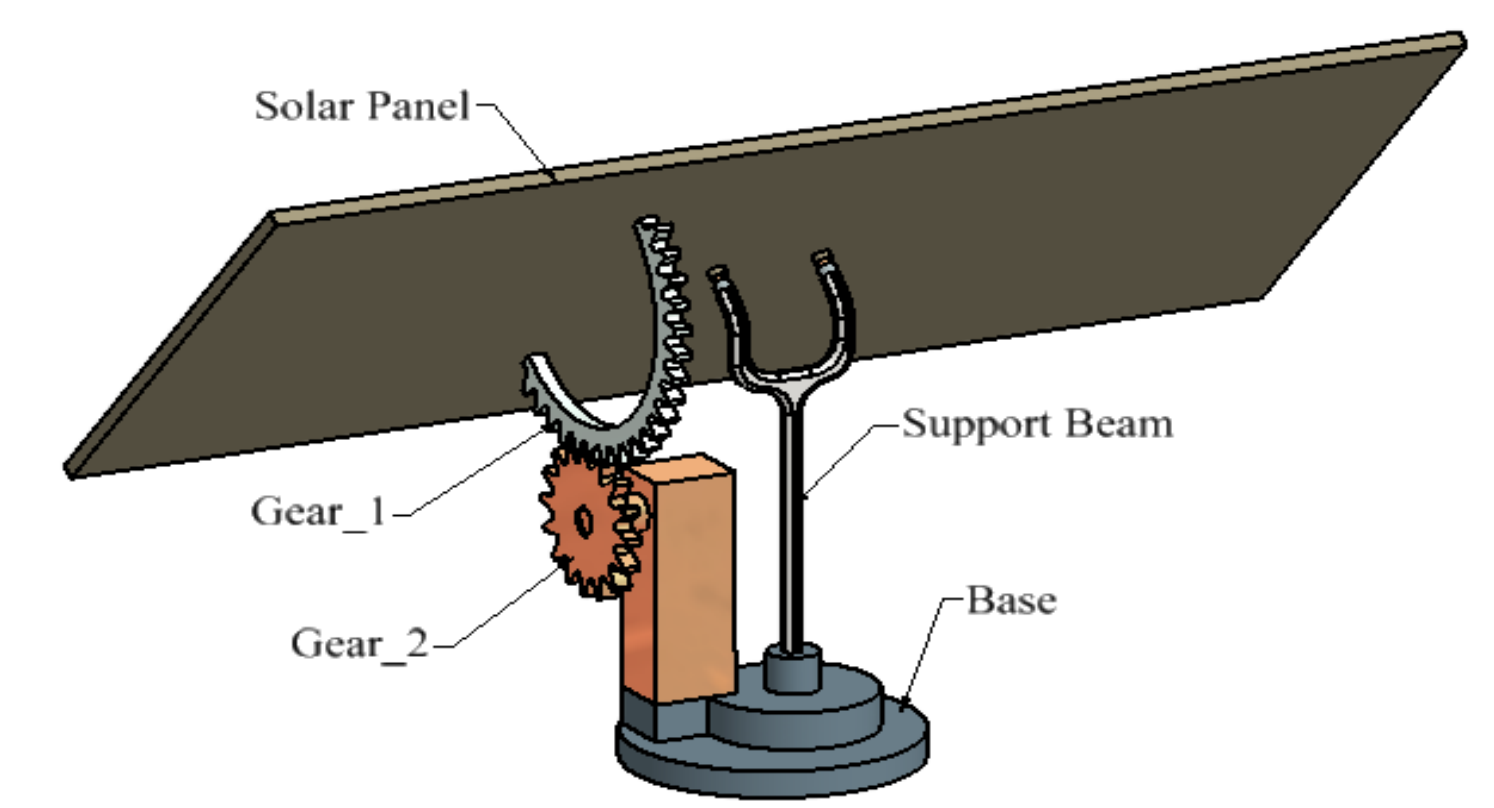

Fig. 1 New solar tracking mechanism
The solar panel is mounted at the top of support beam through the universal flexible hinges. The support beam is installed on a rotary table that is fixed in the base through the thrust bearing. The azimuth stepper motor can transmit the power to the support beam through rotary table and gear_2 can drive gear_1 through gearbox which can orientate solar panel in 3-D rotations.

The structural calculation and analysis are necessary to make sure that this new solar tracking mechanism can function properly to handle strong wind and heavy snow in severe weather conditions. Based on "Minimum Design Loads for Buildings and Other Structures" in ASCE7-10 standard [13], the following analytic results can be determined.

1. Snow load:

$$
\mathrm{Ps}=0.7 * \mathrm{Ce} * \mathrm{Ct} * \mathrm{Is} * \mathrm{Pg}
$$

Here,

Ground snow loads, $\mathrm{p}_{\mathrm{g}}$ - used to determine the design snow loads for solar panel

Exposure Factor, $C_{\mathrm{e}}=0.9$ (Table 7-2 of ASCE7-10 standard) Thermal Factor, $C_{\mathrm{t}}=1.2$ (Table 7-3 of ASCE7-10 standard) Importance Factor, $I_{\mathrm{s}}=1.2$ (Table 1.5-2 of ASCE7-10 based on the Risk Category from Table 1.5-1 of ASCE7-10 standard)

2. Wind load

$$
\mathrm{Pw}=\mathrm{Qz} * \mathrm{G} * \mathrm{Cf}
$$

Velocity pressure, $Q_{z}$ - evaluated at height $z$ (Section 29.3 of ASCE7-10 standard)

Gust-effect factor, $\mathrm{G}=0.85$ (Section 26.9 of ASCE7-10 standard)

Force coefficients, $C_{f}=2.98$ as $\mathrm{h} / \mathrm{D}<1.3$, h is the height of the panel and $\mathrm{D}$ is the diameter of least horizontal dimension of square, (Figs. 29.5-1 through 29.5-3 of ASCE7-10 standard)

$$
\mathrm{Qz}=0.613 * \mathrm{Kz} * \mathrm{Kzt} * \mathrm{Kd}^{*} \mathrm{~V}^{2}
$$

Here,

Wind directionality factor, $\mathrm{K}_{\mathrm{d}}$ (Section 26.6 of ASCE7-10 standard)

Velocity pressure exposure coefficient, $\mathrm{K}_{\mathrm{z}}$ (Section 29.3.1 of ASCE7-10 standard)

Topographic factor, $\mathrm{K}_{\mathrm{zt}}$ (Section 26.8.2 of ASCE7-10 standard) Wind speed, V (Section 26.5 of ASCE7-10 standard) Based on section 26.8.1, $\mathrm{K}_{\mathrm{zt}}=1.0$ and $\mathrm{V}=45 \mathrm{~m} / \mathrm{s}$.

$$
\begin{aligned}
& \mathrm{Kz}=2.01 *(\mathrm{Z} / \mathrm{Zg})^{2 / \mathrm{a}}=0.865 \\
& \mathrm{Qz}=0.613 * \mathrm{Kz} * \mathrm{Kzt} * \mathrm{Kd} * \mathrm{~V}^{2}=966.38 \\
& \mathrm{Pw}=\mathrm{Qz} * \mathrm{G} * \mathrm{Cf}=2447.8 * \mathrm{~Pa}
\end{aligned}
$$

The computer aided simulation can be applied using above mathematical models to perform structural analysis. The Figs. 2 -7 shows the stress and deflection profiles for major components including gear_1, gear_2 assembly, and support beam.

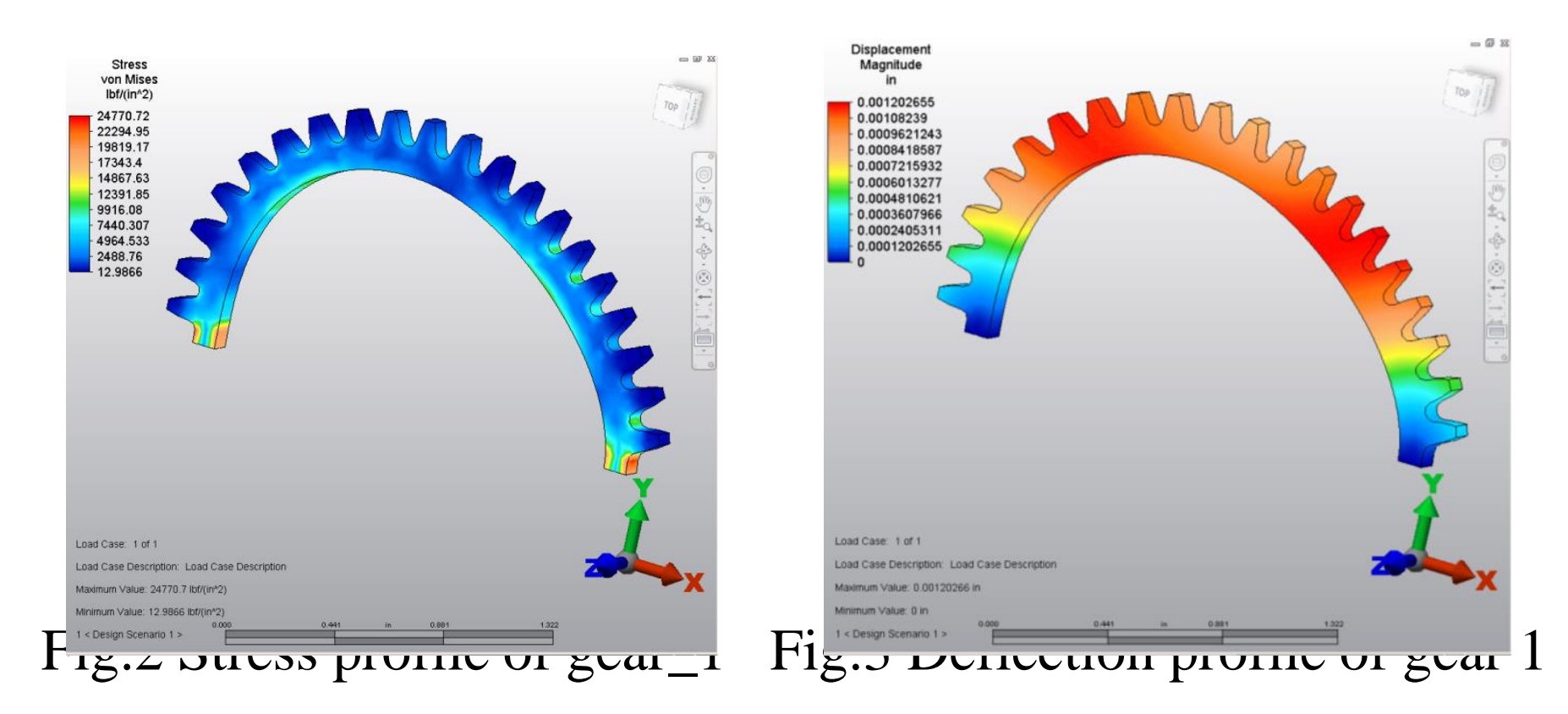

As shown in Figs $2-3$, the maximum stress produced in gear_1 is 24770.72 psi which is lower than the yield strength 57000 psi of gear steel 4026 and deflection is within the material allowable deformation limit, As a result, the gearlcan work well under given conditions of external loads including wind, snow, and dead weight loads in the severe weather.

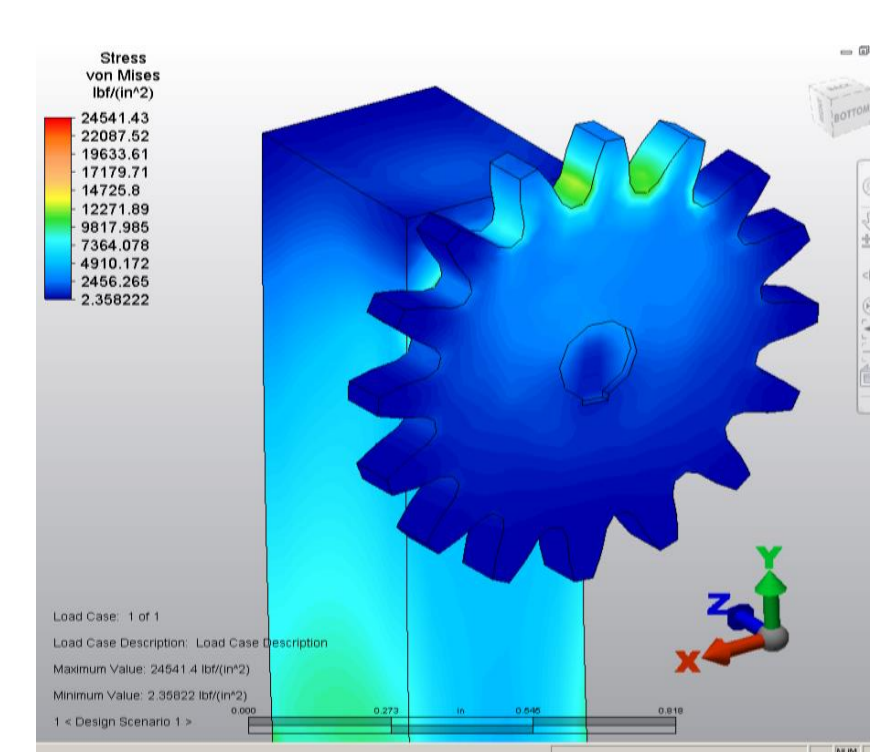

Fig. 4 Stress profile of gear_2 assembly

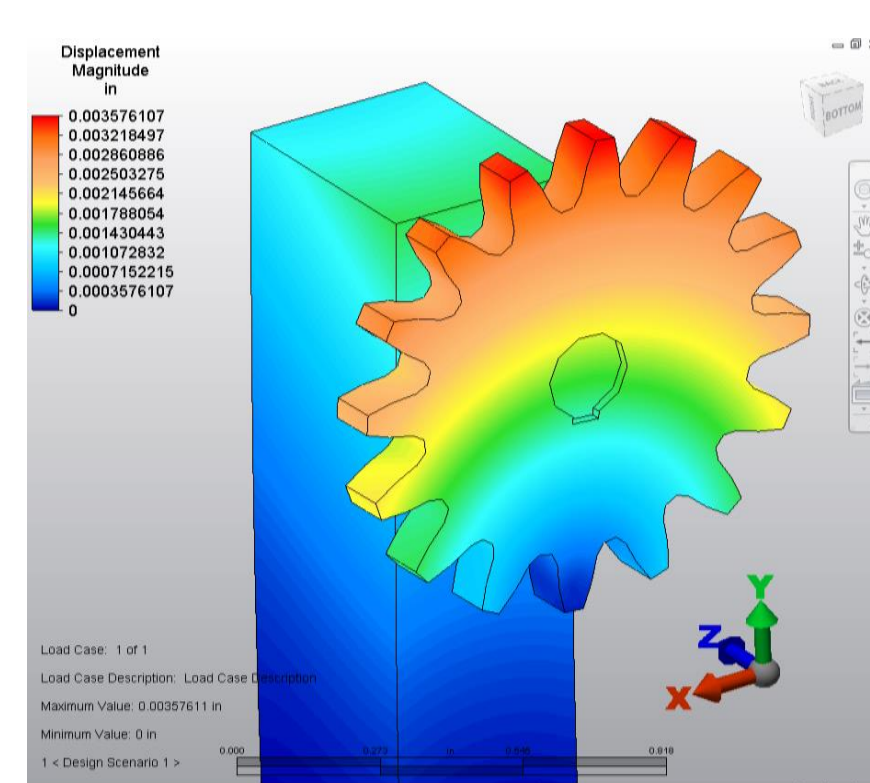

Fig. 5 Deflection profile of gear_2 assembly
Since the stepper motor shaft is also a support for the solar panel tracking system, the structural analysis is required to be performed on both gear_2 and stepper motor shaft. The simulation results shows that, under given loads of snow, wind, and dead weight, the maximum stress generated in gear_2 assembly is 24541.43 psi that is lower than yield strength of gear and shaft materials and the maximum deflection is within the material allowable deformation limit. This means that the gear_2 assembly can function properly in the snowy or windy weather.
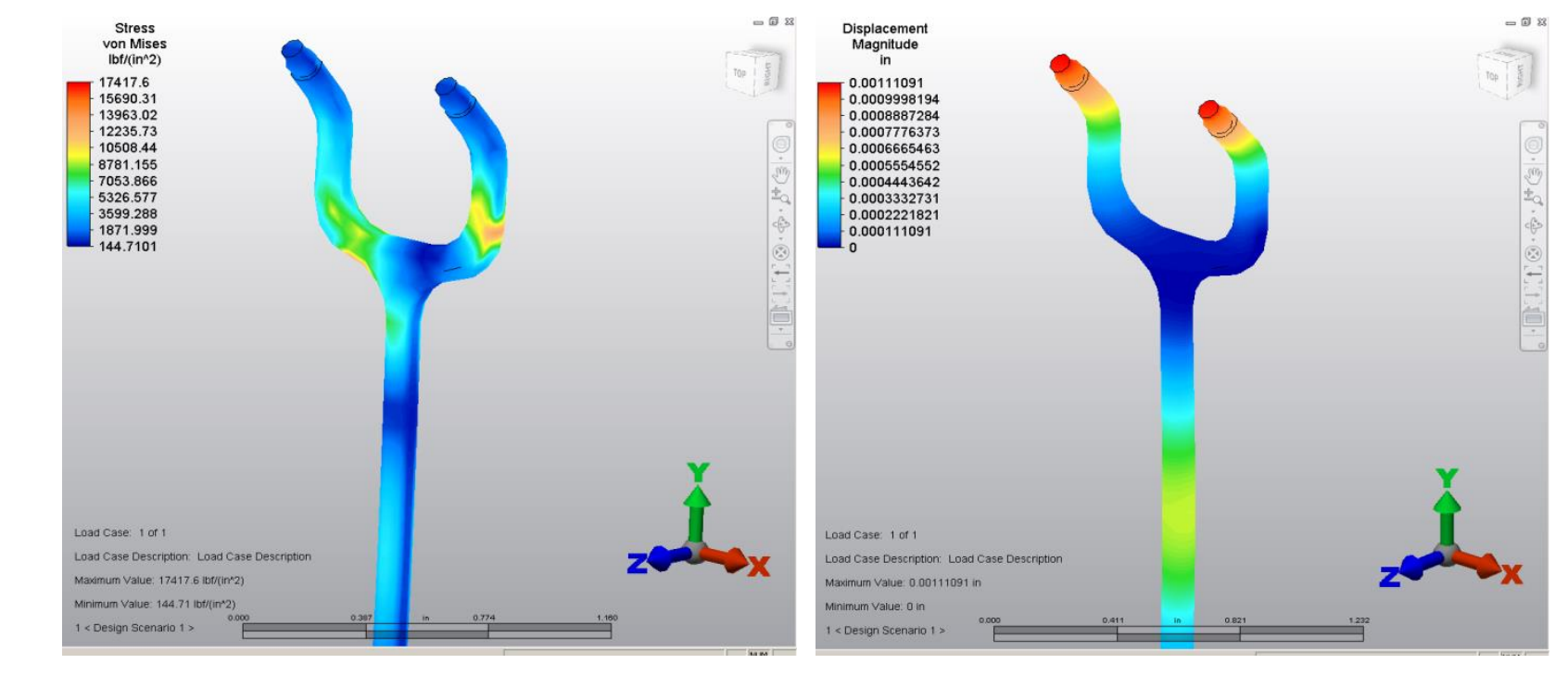

Fig.6 Stress profile of support Fig.7 Deflection profile of beam support beam

The support beam is one of the main support elements in solar panel tracking system which holds the most weight and handle external loads of the panel system. The ball hinge structure allows the 3-D flexible orientation of solar panel system. The support beam is made of A36 steel. Considering the given full loads from snow, wind, and dead weight, the computer simulation presented the stress profile and deflection profile in Figs. 6 - 7. The maximum stress produced in support beam is 17417.60 psi which is lower than material yield strength 36300 psi of A36 and the maximum deflection is within the material allowable deformation limit. It shows that the support beam in this new design can well handle the resultant external and internal loads in the solar tracking operation.

\section{PROTOTYPE TESTING}

To verify this new solar panel tracking system design and above computer aided modeling and simulation, a prototype has been built and tested. The Table 1 present the experimental results on gear_1, gear_2 assembly, and support beam in this new system design.

Table 1 Prototype testing of gear_1

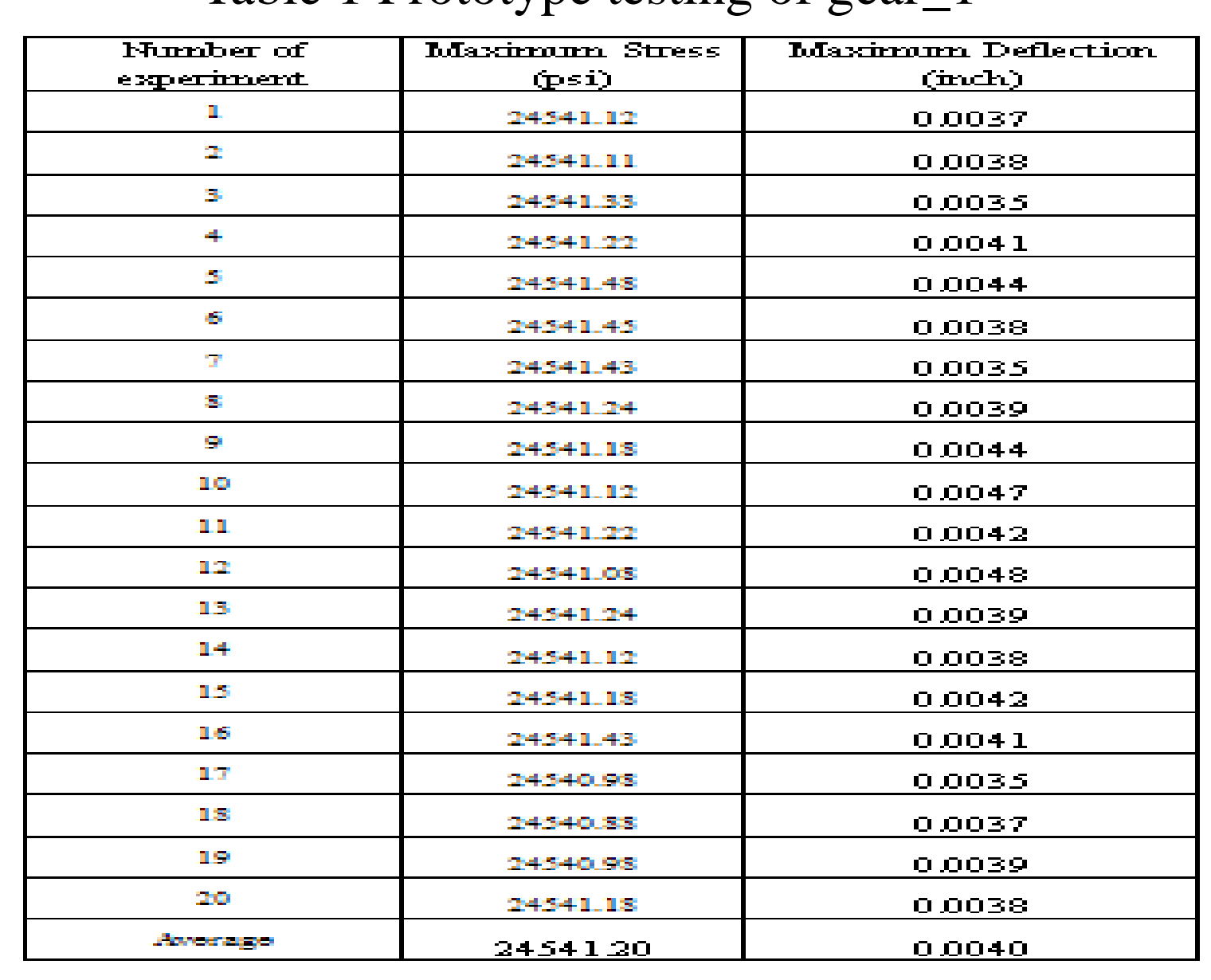

The experiment shows the close results compared to the computer aided modeling and simulation.

\section{CONCLUSION}

Narrative/figure/table Solar energy is a green and sustainable energy resource which can tremendously trim down the use of environmental energy resources including coal and petroleum. The solar energy can be collected more effectively in solar panel system by applying efficient solar tracking system. A new type of solar tracking system introduced in this paper has been studied by 3-D modeling, computational simulation and analysis, and prototype experiment to verify its feasibility and functionality to efficiently capture the solar energy from sunlight. Also the theoretical and experimental studies indicate that this new solar tracking system can well handle the snow and wind loads in severe weather conditions. Both computer aided simulation and prototype experiment demonstrate very close results which validate the credibility of proposed research methodology applied in this new solar tracking system design and development. 